\title{
Formação continuada de pedagogos escolares: 0 significado de grupo e comunicação na prática pedagógica'
}

\author{
Continuing education of school pedagogues: the meaning of group \\ and communication in pedagogical practice
}

\section{Formación continua de pedagogos escolares: el significado de grupo y la comunicación en la práctica pedagógica}

\author{
Evelise Maria Labatut Portilho² \\ Pontificia Universidade Católica do Paraná, Curso de Pedagogia e Programa stricto sensu em Educação, Professora Titular. \\ https://orcid.org/0000-0003-4557-0130 \\ Isabel Cristina Hierro Parolin ${ }^{3}$ \\ Pontificia Universidade Católica do Paraná, Curso de Psicopedagogia, Professora convidada. https://orcid.org/0000- \\ 0002-5518-5925 \\ Laura Monte Serrat Barbosa \\ Pontifícia Universidade Católica do Paraná, Curso de Psicopedagogia, Professora convidada. \\ https://orcid.org/0000-0002-0503-5064
}

Resumo: Ao considerar que o pedagogo é o profissional que articula a comunicação e coordena os grupos envolvidos no processo de ensinar e aprender na escola, este artigo tem como objetivo identificar a articulação que os pedagogos estabeleceram entre as informações recebidas ao longo da formação continuada, as vivências reflexivas sobre comunicação e grupo e a prática já desenvolvida no espaço da escola. A pesquisa, de caráter qualitativo, apresenta a descrição de uma experiência de formação continuada com pedagogos e interpreta os fenômenos à luz da fenomenologia hermenêutica. Para a descrição e interpretação dos dados utilizou-se a roda de conversa de dois encontros da Formação Continuada e uma tarefa a ser realizada na escola. Os resultados indicam que os participantes da pesquisa, por não trabalharem, na maioria das vezes, sob a ótica da observação e

Todas as autoras contribuiram igualmente na elaboração deste artigo. A pesquisa que o origina é financiada pela Fundação Araucária (FA) - Projeto 001/2017 - Pesquisa Básica Aplicada.

2 Pós-doutora em Educação pela Universidade do Porto (Portugal); Doutora em Educação pela Universidade Complutense de Madri (Espanha).

3 Mestre em Educação pela Pontificia Universidade Católica de São Paulo; Graduada em Pedagogia pela Pontifícia Universidade Católica do Paraná.

4 Mestre em Educação pela Universidade Federal do Paraná; Especialista em Psicologia Escolar e da Aprendizagem pela Pontificia Universidade Católica de Campinas. 
da escuta, e também por não estarem respaldados pelo conhecimento de que a escola deveria ser entendida como um grupo, em processo dinâmico e que é impossivel não comunicar, acabam fazendo leituras da dinâmica escolar e de seus fenômenos, de modo simplista.

Palavras-chave: Formação Continuada. Pedagogo. Escola. Grupo. Comunicação.

Abstract: Considering that the pedagogue is the professional who articulates communication and coordinates the groups involved in the process of teaching and learning at school, this article aims to identify the articulation that the pedagogues established between the information received during the continuing education, the experiences reflections on communication and group and the practice already developed in the school space. This qualitative research presents the description of an experience of continuing education with pedagogues and interprets the phenomena in the light of hermeneutic phenomenology. For the description and interpretation of the data we used the conversation wheel of two meetings of Continuing Education and a task to be performed at school. The results indicate that the research participants, for not working most of the time from the perspective of observation and listening, also because they are not supported by the knowledge that the school should be understood as a group, through a dynamic process, which is impossible not to communicate, end up reading the school dynamics and its phenomena in a simplistic way.

Keywords: Continuing education. Pedagogue School. Group. Communication.

Resumen: Al considerar que el pedagogo es el profesional que articula la comunicación y coordina los grupos involucrados en el proceso de enseñanza y aprendizaje en la escuela, este artículo tiene como objetivo identificar la articulación que los pedagogos establecieron entre la información recibida durante la formación continua, experiencias reflexivas. sobre la comunicación y el grupo y la práctica ya desarrollada en el espacio escolar. La investigación, de carácter cualitativo, presenta la descripción de una experiencia de educación continua con pedagogos e interpreta los fenómenos a la luz de la fenomenología hermenéutica. Para la descripción e interpretación de los datos, se utilizó la rueda de conversación de dos encuentros de Educación Continuada y una tarea a realizar en el colegio. Los resultados indican que los participantes de la investigación, por no trabajar, la mayor parte del tiempo, desde la perspectiva de la observación y la escucha, y también porque no se apoyan en el conocimiento de que la escuela debe entenderse como un grupo, en una dinámica y que es imposible no comunicarse, terminan leyendo la dinámica escolar y sus fenómenos, de manera simplista.

Palabras clave: Educación Continuada. Pedagogo. Colegio. Grupo. Comunicación.

Recebido em 2 de junho de 2020 Aceito em 3 de dezembro de 2020 


\section{INTRODUÇÃO}

Na contemporaneidade, a tecnologia tem aproximado os distantes e distanciado os que estão próximos. Os recursos digitais, em seu processo comunicativo, facilitam e agilizam o cotidiano. Alguns deles são dotados de inteligência artificial feita para representar, da maneira mais próxima possível, uma pessoa de verdade. No entanto, não trabalham com a percepção empática que dá sentido próprio aos fenômenos, com a inteligência social que possibilita a adaptação às situações no momento do acontecimento e não conseguem criar, diante do inusitado, uma alternativa que flexibilize a tomada de decisão. Exemplos de tais recursos são a Siri da Apple, a Bixby da Samsung, a S Voice da Google e tantas outras personagens que só conseguem responder a perguntas cujas respostas podem acessar na web; quando interrogadas sobre algo pessoal, dão respostas desconexas, uma vez que não são programadas para tal, pois não são sensiveis.

No entanto, ainda que os espaços virtuais estejam em ascensão, é indiscutível a importância dos espaços presenciais, como a escola, objeto deste estudo. Seus protagonistas são pessoas que agem, interagem, expressam sentimentos e ideias, e este ambiente reúne pessoas com o objetivo de promover a aprendizagem de todos que a compõem. A escola é uma instituição constituída por grupos, e sendo assim se caracteriza como uma unidade em funcionamento, um grande grupo.

0 pedagogo é o profissional que articula a comunicação e coordena os grupos envolvidos no processo de ensinar e aprender. Destaca-se, nesse sentido, que a escola é um grupo que apresenta uma modalidade de comunicação que a identifica e a caracteriza, e o pedagogo é o profissional que articula esse processo. Como articulador e coordenador de grupos na escola, o pedagogo precisa, em sua formação, conhecer o funcionamento destes para assim poder provocar a articulação da visão individual, prevalente no mundo atual, à visão da coletividade. Sendo assim, é importante para esse profissional aprender a intervir em situações grupais, visando a uma comunicação e uma ação voltadas para a realização dos objetivos centrais da instituição em que trabalha e dos grupos em que atua.

Com base nessa perspectiva, a Pesquisa Aprendizagem e Conhecimento na Identidade Profissional do Pedagogo ofereceu um programa de formação continuada a pedagogos de diferentes redes de ensino, no $2^{\circ}$ semestre de 2018 . Um dos temas trabalhados foi o de "grupo como unidade em funcionamento". Esse conceito nos fala de pessoas em movimento, na direção de um fazer comum. Na escola, essa construção é realizada e coordenada, entre outros profissionais, pelo pedagogo, e objetiva o aprender e o ensinar como um processo, que envolve todos os protagonistas que a compõem. 
Outro conceito desenvolvido na referida formação foi a comunicação, visto que um grupo nela se constitui. Na escola, a comunicação nos grupos e dos grupos entre si possibilita a integração horizontal e vertical do processo educativo. Sendo assim, ao selecionar dois temas que subsidiaram a formação continuada de pedagogos escolares grupo e comunicação - tem-se como objetivo neste artigo identificar a articulação que os pedagogos estabeleceram entre a informação recebida, as vivências reflexivas durante a formação continuada sobre comunicação e grupo e a prática já desenvolvida no espaço da escola. Tudo isso sem perder a visibilidade de que o processo de formação continuada pode ter ampliado não apenas o conceito, mas, sobretudo, o modo como a prática nas escolas, em que os pedagogos atuam, acontece.

\section{A COMUNICAÇÃO NA ESCOLA}

Com base nos pressupostos da teoria sistêmica, que substitui o modelo linear do pensamento causa e efeito pelo modelo circular, interativo, ao tentar entender um grupo e planejar intervenções, necessita-se desvelar a qualidade das relações que esse grupo estabelece.

0 presente estudo pautou-se para isso no conceito de comunicação, na formação continuada dos pedagogos e na visão do psicólogo social Pichon-Rivière (2005, p. 131) pelo fato de esse autor se preocupar em entender a comunicação nos grupos:

\footnotetext{
Podemos dizer que a comunicação é um contexto que inclui um mundo de sinais que todos aqueles que se intercomunicam podem codificar e decodificar da mesma maneira. [...] ao assinalar que estes processos de codificação e decodificação de sinais pertencem a esquemas referenciais individuais e dos grupos, através dos quais se torna possivel, de acordo com o funcionamento e estrutura destes esquemas, configurar situações de entendimento e mal-entendido. Em última instância, a comunicação grupal é possivel pela existência de um esquema conceitual, referencial e operativo de caráter grupal.
}

Para o autor, os processos de comunicação e aprendizagem coexistem, entrelaçam-se e cooperam entre si, e tal compreensão pode contribuir para a eficácia na coordenação de grupos.

Na preparação para os estudos desenvolvidos no Grupo de Pesquisa e nas discussões realizadas classificou-se a comunicação interpessoal, no ambiente escolar, em quatro grandes grupos: comunicação interpessoal - corredor; comunicação interpessoal - 
em grupo; comunicação interpessoal - verbal e não verbal (corporal); comunicação por meio da mídia e da tecnologia.

Entendeu-se que a comunicação em corredor pode acontecer nas relações interpessoais tanto quando realizada entre duas pessoas como entre uma pessoa e vários interlocutores. Essa forma de comunicação pode se apresentar de distintas formas: ouvir e ser ouvido; acontecer em função da tarefa do grupo; colaborar ou não com o que já foi dito até o momento, trazendo novos dados; promover ou não a oposição ao que está sendo tratado - desconstruindo e reconstruindo conceitos; articular ou não diferentes pontos de vista; provocar o pensamento e a ação grupal. Trata-se de um processo dinâmico, e sua eficiência comunicativa é construída pelo próprio movimento do grupo.

0 pedagogo, como coordenador de grupo, precisa desenvolver uma atitude que crie, mantenha e fomente a comunicação entre os participantes da escola. Essa atitude foi denominada por Jorge Visca, ${ }^{5}$ em suas aulas, como "atitude operativa". Isso pede, daquele que coordena ações de aprendizagem, uma atitude tal que leve o aprendiz a se movimentar em direção àquilo que será aprendido (BARBOSA, 2007).

Nesse sentido, a comunicação é realizada por meio da oralidade e não apenas mediante as palavras que estão sendo ditas, mas também pelas expressões que as acompanham, pelos gestos que predominam, pelo tom com o qual são ditas, pelo significado que têm para determinado grupo, pelo sentido que elas têm para as diferentes pessoas. Essas atitudes vão sendo adotadas na medida em que aquele que coordena o grupo, no caso o pedagogo, observa tanto o que é dito (temática) quanto o movimento que aparece de forma não verbal (dinâmica).

Na pragmática da comunicação humana, outro aporte teórico deste trabalho, essas duas formas de comunicação são identificadas, respectivamente, como "digital" e "analógica".

A segunda é não verbal. Refere-se ao modo, aos gestos, ao tom de voz, aos olhares, à expressão facial, ao estilo do silêncio, à cadência das palavras, ao tom das palavras, à velocidade dos gestos. Pode ser ambígua, assim como está sob a égide da interpretação de outro, que fará essa leitura com base em seu repertório pessoal e em seu esquema conceitual referencial operativo.

Um exemplo desse tipo de comunicação aconteceu em uma escola na qual a pedagoga solicitou aos professores que desenvolvessem um projeto com os grupos de alunos. 0 professor novo utilizou o esquema que havia sido discutido na reunião de planejamento como uma obrigatoriedade e não conseguiu a mobilização dos alunos. Outros professores

Jorge Visca, psicopedagogo argentino, criou a teoria denominada Epistemologia Convergente. Para obter mais informações sobre o assunto, ver: Visca (1987). 
partiram do esquema construído e o foram transformando por meio da discussão com os grupos de alunos. Nesse sentido, a consigna expressa pela pedagoga foi a mesma, no entanto, cada professor significou e agiu àquela comunicação considerando sua experiência em relação à natureza das relações já estabelecidas com a autoridade, além da forma de trabalhar com projetos.

Já a comunicação digital é constituída por expressões verbais organizadas de acordo com uma sintaxe lógica, no entanto pouco eficiente para expressar a emoção e sua repercussão nas relações. Envolve a linguagem e seu significado social, porém carece de sentido pessoal para ajudar na compreensão.

Um exemplo dessa comunicação refere-se a uma pedagoga que enviou um recado para a mãe de uma aluna pedindo a ela que comparecesse à escola "o quanto antes". A mãe, logo após ler o bilhete, ligou para a escola solicitando um horário para conversar com a professora, afirmando ser urgente. A pedagoga, assustada com a urgência da mãe, logo a atendeu. Quando ambas se reuniram, perceberam que cada uma delas entendeu que a urgência era da outra. Observa-se desse modo que a linguagem escrita pode não trazer o tom da mensagem e por isso os sentidos podem ser distorcidos, assim como as intenções do emissor.

Watzlawick, Beavin e Jackson (1999, p. 61) apresentam uma síntese elucidativa sobre esses dois tipos de comunicação:

\footnotetext{
Os seres humanos comunicam digital e analogicamente. A linguagem digital é uma sintaxe lógica sumamente complexa e poderosa, mas carente de adequada semântica no campo das relações, ao passo que a linguagem analógica possui a semântica, mas não uma sintaxe adequada para a definição não ambígua da natureza das relações.
}

Diante disso, as intervenções nos grupos de trabalho devem observar a comunicação por meio da temática, referente à linguagem digital, e da dinâmica, referente à linguagem analógica.

As relações sempre geram algum tipo de comunicação, e considerando o entendimento da teoria da pragmática da comunicação humana, tanto a comunicação quanto a conduta são tratados como sinônimos. Salienta-se, também, que a comunicação nem sempre é bem-sucedida, intencional ou, ainda, consciente, pois o comportamento sempre desvela a intenção. Nessa perspectiva, afirma-se que não existe o não comportamento, o que reforça a afirmativa de que sempre uma pessoa irá comunicar algo.

Toda conduta está ligada a um contexto interativo qualquer, dando espaço para que se afirme, com base na perspectiva da pragmática da comunicação humana, que é 
impossivel não comunicar. Parte-se, então, do pressuposto de que toda mensagem contém um conteúdo, o modo como esse conteúdo é comunicado e é expressa em forma de um comportamento. Sendo assim, os processos interativos acontecem durante as trocas de mensagens, em forma de discurso ou de silêncio, de gestos, de olhares, da evitação, que podem ser lidos por todos de maneira diferente.

Considerando a comunicação na escola é um instrumento de ação do pedagogo, esse tema foi escolhido para a formação continuada dos pedagogos escolares utilizando-se da roda de conversa como técnica que permite a vivência da comunicação e a sensibilização para o trabalho com seus grupos.

A roda de conversa, em sua essência, promove um espaço no qual as pessoas que compõem o grupo se manifestam, comunicam o que pensam, sentem e o modo como interagem com o conhecimento e as pessoas (SAMPAIO et al., 2014).

Nas relações humanas é impossível não comunicar. Considerando que o compromisso central do pedagogo é ser o articulador do processo de ensino e aprendizagem e, como tal, coordenador de diferentes grupos da instituição escola, fará parte de sua função promover e observar as interações, as mensagens e a forma como a comunicação se estabelece.

A ideia de grupo como um conjunto de pessoas capazes de se reconhecer em suas individualidades e especificidades, experienciada pelos pedagogos em formação continuada, pode subsidiá-los no sentido de compreender a escola como um espaço constituído por grupos.

\section{A ESCOLA COMO UM ESPAÇO DE GRUPOS}

0 conceito de grupo enquanto unidade em funcionamento integra conhecimentos da sociologia à conceituação de vínculo e entende o grupo como uma reunião de pessoas que têm um objetivo comum e permanecem juntas para atingi-lo (PICHON-RIVIĖRE, 2005). Assim, realizam uma tarefa, que é objetiva e externa, ao mesmo tempo em que, no exercício das relações, é também subjetiva e interna, já que toda ação conjunta provoca ansiedades. A diversidade de histórias pessoais, as distintas ideias e vivências pedem a inter-relação das pessoas que se propõem resolver as situações apresentadas, compartilhando essas ideias e vivências, esses saberes e sentimentos, o que mobiliza emoções, afetos e desafetos a serem trabalhados no percurso da realização da tarefa grupal. 
Os grupos que constituem o espaço escolar também funcionam assim professores chegam de diversos lugares, com diferentes formações, com histórias distintas, mas todos com a tarefa de promover a aprendizagem. Assim também acontece com o grupo de alunos, o de pais e o de colaboradores, todos formados por pessoas distintas, que viveram histórias bem diferentes, mas que se reúnem com objetivos semelhantes, sendo o que os move e como vivem a ação comum o que os caracteriza como grupo.

0 pedagogo, dependendo da escola e da maneira como ela é organizada, pode ser responsável por um desses grupos ou por todos eles, não perdendo a perspectiva de que todos interagem em um processo dinâmico. E sua competência para avaliar o momento de um grupo, intervir quando necessário para promover aprendizagens ou, ainda, deixar o grupo viver seu momento de caos, precisa ser aperfeiçoada constantemente para estimular a cooperação, a autonomia e a realização das tarefas específicas dos grupos. Ou seja, a tarefa dos professores é requerer a aprendizagem por meio do ensino; a tarefa do aluno é aprender por meio do que a equipe docente traz como possibilidades; já a tarefa dos pais é conhecer a proposta da escola e valorizá-la junto a seus filhos, participar no que for relevante. A tarefa dos colaboradores é com a gestão administrativa da escola, ao mesmo tempo em que atuam com a equipe docente para que os alunos aprendam. Configura, portanto, um processo colaborativo, na concepção de grupo considerada por este artigo.

Nesse sentido, o pedagogo, como coordenador de grupos, necessita desenvolver duas habilidades importantes - observação e intervenção. Afinal, para entender o movimento de grupo ele precisa aguçar seu olhar e sua escuta, implicados em uma boa observação e um aporte teórico que sustente essa dinâmica. 0 olhar o permite observar a dinâmica do grupo: o movimento em direção à tarefa, as inter-relações entre os participantes do grupo, os movimentos de cooperação e de competição que podem aparecer, a escolha de elementos para realizar o que precisa ser realizado, os papéis desempenhados pelos participantes, os pontos de tensão e de relaxamento e outros fatores que podem contribuir ou ser um obstáculo para o processo da tarefa de aprender e ensinar na escola. Já a escuta o possibilitará captar a temática do grupo: por meio de tudo que é falado, dos diálogos, dos monólogos, das verbalizações desencontradas, do conteúdo do que é dito e dos tons com que as mensagens verbais são produzidas e encaminhadas. Olhar e ouvir o movimento grupal só terá sentido se o que for visto e ouvido puder ser analisado para que o coordenador possa, de fato, compreender o que acontece e assim intervir.

Essa análise pode ser realizada tendo com referencial os elementos do cone invertido apresentado por Pichon-Riviére (2005): grau de pertencimento, de cooperação, de eficácia, qualidade da comunicação, da aprendizagem e da aproximação afetiva dos participantes do grupo em relação à tarefa. 
Sendo assim, o movimento observado e o que é comunicado com palavras podem contribuir para o pedagogo compreender o que está acontecendo no grupo. Por exemplo: em uma reunião de professores, muitos se queixam do $7 .^{\circ}$ ano pelo desinteresse que os alunos apresentam, pela divisão que aparece na sala entre meninos e meninas e pela comunicação sarcástica que se estabelece entre eles e muitas vezes em relação aos professores. Essa queixa pode ser entendida como um motivo para que o pedagogo sugira o que será feito pelos professores, mas pode também ser entendida como um motivo para que o pedagogo proponha à equipe docente repensar e reavaliar a situação. Utilizando os elementos do cone invertido, o pedagogo questiona-se sobre o grau de pertencimento dos alunos no grupo classe, o grau de cooperação dos alunos com o que precisa ser aprendido, a eficácia das tarefas realizadas, a forma de comunicação que predomina no grupo, as resistências do grupo, os interesses que se destacam, o clima afetivo que existe entre os alunos e entre eles e os diferentes professores.

As perguntas podem ajudar o grupo de professores a pensar de que forma será possível atingir os alunos e o interesse da turma. Perguntar é uma das formas mais eficientes de intervir em um grupo que se encontra queixoso e obstaculizado pela queixa. Por meio de perguntas, o pedagogo pode contribuir para o desenvolvimento da observação dos professores e professoras. No entanto, existem outras formas de intervir chamadas por Portilho et al. (2018, p. 47) de "atitudes operativas", que o(a) pedagogo(a) pode adotar para promover a ação e a autonomia dos grupos que coordena.

\footnotetext{
Aprendemos em nossa prática a desenvolver uma atitude pela qual as pessoas se colocam em movimento para aprender, sem ficar em uma relação de dependência resultante de uma educação autoritária e /ou permissiva. Atitude Operativa é provocar aquele que aprende a apropriarse da sua forma de aprender agindo sobre ela e sobre o objeto a ser aprendido, com o maior grau de autonomia possivel, naquele momento, naquele contexto, com aquelas pessoas.
}

Embora as autoras se refiram a atitudes operativas a serem utilizadas por psicopedagogos na instituição, pode-se estender esse saber aos pedagogos e a outros profissionais que coordenam grupos.

As atitudes operativas a serem utilizadas pelo pedagogo podem ser: questionar em vez de sempre dizer o que é para ser feito; trazer informações pertinentes ao momento para aumentar as possibilidades de solução dos problemas trazidos; oferecer alternativas para que o grupo possa escolher o melhor caminho entre os possíveis; valorizar o conhecimento já existente para provocar seu aprofundamento ou ampliação; mudar as situações para que as pessoas possam modificar seus pontos de vista; permitir aos grupos que vivam seu 
não saber para que criem iniciativas de busca do saber; promover revisitas ao processo de aprender do grupo para que possa haver a identificação dos avanços existentes e a identificação do que ainda pode ser aprendido; promover o levantamento de hipóteses diante de um problema e receber com interesse as hipóteses levantadas pelo grupo, visando à importância da confirmação ou não das mesmas e ainda formular intervenções que levem o grupo a se centrar na tarefa comum.

Obviamente que essas atitudes operativas não são indicações a serem seguidas cegamente, mas sugestões de como mobilizar um grupo e levá-lo a se sentir autor daquilo que precisa realizar na escola para atender a tarefa principal da instituição, que é aprender e ensinar.

\section{METODOLOGIA}

Este artigo faz referência a uma pesquisa de caráter qualitativo, que por sua vez apresenta a descrição de uma experiência de formação continuada com pedagogos escolares, interpreta os fenômenos à luz da fenomenologia hermenêutica e revela os fatos por meio dos relatos na busca por interpretá-los com reflexão (COLTRO, 2000). A proposta não apenas descreve as vozes, as falas e a linguagem dos sujeitos, mas interpreta o que $\circ$ ambiente educativo comunica.

0 contexto da pesquisa consistiu em um programa de formação continuada para pedagogos escolares oferecido pelo Grupo de Pesquisa Aprendizagem e Conhecimento na Prática Docente no $2 .^{\circ}$ semestre de 2018 , em oito encontros quinzenais, de duas horas cada. Esse tempo foi dividido em três momentos: disparador (dinâmica de grupo e apresentação do referencial teórico relativo ao tema do dia); roda de conversa (iniciava como uma consigna preparada antecipadamente); avaliação metacognitiva (questionário preparado especialmente para a formação e aplicado no final de todos os encontros).

Os temas dos encontros foram escolhidos com base na realidade dos participantes. São eles: Apresentação do Projeto; Formação Continuada e Autoformação; Identidade Profissional do Pedagogo; Comunicação Inovadora e Integradora; A Expressão da Cultura no Ambiente Educativo; Grupo - uma unidade em funcionamento; Mediação no Processo de Aprendizagem e Ensino; Avaliação e Registro.

A dinâmica dos encontros favorecia um movimento metacognitivo, isto é, os participantes saíam da posição de ouvintes e se colocavam como autores do processo ao serem convidados a tomar consciência de sua identidade e se autorregularem em relação a ela como pedagogos escolares (CUNHA; BORUCHOVITCH, 2016). 
Para participar do Programa de Formação Continuada foram convidados vinte e cinco pedagogos que trabalhavam em instituição escolar. A elaboração deste artigo contou com os dados de dezesseis profissionais, os quais concluíram a primeira etapa da pesquisa. Para manter o anonimato dos participantes eles são denominados a partir da sigla $\mathrm{P}$, seguida de um número.

Os instrumentos elaborados para a formação foram diversos, mas para esse momento foram selecionados os registros da roda de conversa do $4 .^{\circ}$ e $6 .^{\circ}$ encontros e também a tarefa do $6 .^{\circ}$ encontro, a saber, "Observar um grupo de professores de sua escola em determinada tarefa e destacar, por escrito, elementos que o caracterizam como uma unidade em funcionamento, ou seja, como um grupo." Em todos os encontros o grupo de pedagogos recebeu uma atividade para ser realizada no intervalo entre um encontro e outro, a qual foi denominada de "tarefa".

A pesquisa contou com a aprovação do Comitê de Ética em Pesquisas com Seres Humanos da Pontifícia Universidade Católica do Paraná (CAAE n. $\left.{ }^{\circ} 87390517.8 .0000 .0020\right)$.

\section{DESCRIÇÃO E INTERPRETAÇÃO DOS RESULTADOS}

Para a descrição e interpretação dos dados foram utilizados três instrumentos de pesquisa: a roda de conversa do $4 .^{\circ}$ encontro (Comunicação Inovadora e Integradora) e a roda de conversa do $6 .^{\circ}$ encontro (Grupo - uma unidade em funcionamento), assim como a tarefa do 6 . $^{\circ}$ encontro, "Observar um grupo de professores em determinada tarefa e destacar, por escrito, elementos que o caracterizam como uma unidade em funcionamento, ou seja, como um grupo.".

\subsection{RODA DE CONUERSA DO $44^{\circ}$ ENCONTRO}

Ao iniciar a roda de conversa do $4 .^{\circ}$ encontro sobre comunicação, o coordenador apresentou como consigna oral: "A tarefa do grupo será correlacionar a qualidade da comunicação vivida no cotidiano escolar, das instituições aqui representadas, ao que viveram, ouviram, sentiram e pensaram até aqui." (informação verbal).

No registro dessa roda de conversa foram constatadas três categorias de análise. A primeira delas é o predomínio da individualidade - entendida como a comunicação 
centrada em uma pessoa. Ex: "Quem escuta, escuta o que quer." (P8). "Se a secretaria falta, já fragmenta, não chega a informação." (P16) (informações verbais).

Outra categoria levantada está relacionada ao predomínio do excesso de atividades - quando o pedagogo se sente sobrecarregado e acaba por executar tarefas que vão além de suas atribuições. Com isso, acaba por não identificar sua real função na escola. Ex: "0 pedagogo faz tudo e, ao mesmo tempo, não faz nada. Você não tem uma secretária na escola que saiba fazer ata, tudo o pedagogo [...]" (P3) (informação verbal).

Pooli e Ferreira (2017, p. 31), ao pesquisarem sobre a identidade do pedagogo, reforçam a questão do excesso de atividades e da descaracterização da função dele, atualmente, na escola:

0 pedagogo unitário tem que enfrentar a dura realidade do sucateamento da escola pública e a precarização do trabalho pelo oportunismo de muitos gestores que se utilizam da concepção de pedagogo unitário como justificativa ardilosa para corte de pessoal, já que ele foi formado para ser gestor, orientador educacional e supervisor escolar.

0 sucateamento da profissão do pedagogo, não somente na escola pública, como afirmam os autores, resulta na precarização de sua ação, o que pode refletir na organização de suas atividades e na comunicação com seus grupos: pais, professores, alunos e colaboradores. Dito de outra forma, o não enquadramento de sua função e a dicotomização entre a formação inicial e as condições que a prática oportuniza podem repercutir na construção de sua identidade profissional e, consequentemente, na comunicação.

Uma terceira categoria obtida com os resultados da pesquisa - predomínio da integração - revela uma aproximação do grupo com o sentido da comunicação no espaço escolar, como expresso por um dos pedagogos: "A comunicação é o que vai abrir a porta para recuperar o aluno da evasão e reprovação." (P14) (informação verbal). Isso pode significar que o diálogo entre o pedagogo e o grupo de alunos, por exemplo, deve focar na tarefa de aprender, e não nas questões sociais e emocionais, conforme outro pedagogo: "Têm muitos casos em que salvamos vidas, percebemos drogas, prostituição e com isso tomamos o trabalho do psicólogo escolar." (P16) (informação verbal).

Ao longo da conversa estabelecida, o grupo demonstrou permanecer nas queixas na maior parte do tempo, como a preocupação com o excesso de tarefas no cotidiano escolar, não conseguindo explorar a terceira categoria, a da integração. Um dos aspectos ainda insipiente e que gera confusão e desconforto é a inovação tecnológica e a comunicação, como se percebe neste depoimento: "Na escola em que estou agora, o diretor estipulou a criação de um grupo de WhatsApp de pais. Os pais não têm prática do diálogo. Houve 
problemas, não houve reunião, foi difícil no começo." (P16) (informação verbal). Observa-se com isso que a tecnologia nem sempre é adequada e muitas vezes essa inovação é utilizada sem avaliação ou usada para burlar regras.

\subsection{RODA DE CONUERSA DO 6. ENCONTRO}

Ao iniciar a roda de conversa do $6 .^{\circ}$ encontro, o coordenador apresentou como consigna oral: "Com base nos vídeos e conceitos apresentados, o grupo tem como tarefa compartilhar suas experiências como pedagogo e refletir de que forma pode ampliar sua ação como coordenador do grupo de professores." (informação verbal).

$\mathrm{Na}$ interpretação da roda de conversa, por meio da observação da temática (o que o grupo de pedagogos falava) e da dinâmica (como o grupo agia) percebeu-se que os relatos dos pedagogos fizeram emergir três categorias: predomínio da individualidade mostra certo afastamento da concepção da ação coletiva; predomínio da queixa - quando o grupo ocupa o lugar do pensamento com a queixa; predomínio da operatividade - quando o grupo destaca a possibilidade de resolver problemas de forma autônoma e coletiva.

A primeira categoria, predomínio da individualidade, foi observada nas seguintes falas: "Fiz minha parte." (P15); "Eficiência coletiva, faz tempo que não vejo." (P3) (informações verbais).

Campos (2016, p. 130) reforça a importância do trabalho coletivo realizado pelo pedagogo escolar, assim como a visão de grupo desse profissional para superar o individualismo recorrente na fala dos participantes desta pesquisa:

\footnotetext{
as equipes escolares vão se constituindo e fortalecendo ao serem desafiadas a refletir sobre seu próprio trabalho, levantando e discutindo dados sobre o trabalho da própria escola no contexto dos sistemas de ensino; sobre a avaliação desse trabalho; sobre a análise de tal avaliação, definindo princípios éticos, metas e planejamento coletivo para atingi-las, - que implica desafiar a equipe escolar para assumir um posicionamento político-pedagógico coletivamente.
}

A respeito da concepção e formação de grupo, Ávila (2010) salienta que muitas variáveis estão em jogo, mas destaca as relações pessoais, entre cada indivíduo e os demais, assim como entre cada indivíduo e o conjunto dos demais - e as tensões decorrentes disso - como a dimensão mais significativa e própria de grupo. 
Essas tensões dificultam, muitas vezes, ao pedagogo compreender a inter-relação constante entre o indivíduo e o grupo, e é comum que ele entenda o grupo como uma reunião de indivíduos e valorize mais as ações individuais em detrimento das coletivas.

A segunda categoria retirada das falas durante a roda de conversa - predomínio da queixa - foi assumida em muitos momentos, conforme se percebe nas seguintes falas: "Não conseguimos avançar num movimento melhor. 0 grupo permanece sempre com muitas queixas." (P15); "Nosso papel é bem complicadinho, começamos o ano com quinze professoras numa escola que têm oitenta." (P21) (informações verbais).

De acordo com Alícia Fernandes (1994), a queixa é uma forma de inibir o pensamento, a reflexão e a tomada de consciência, o que pode obstaculizar a ação do pedagogo na escola.

Sendo assim, os pedagogos escolares necessitam cuidar para que não caiam no lugar da queixa e possam se utilizar da pergunta para contribuir com a desativação da queixa no espaço escolar, pois, ao mesmo tempo em que ela garante a denúncia de um aborrecimento, também assegura que as coisas continuem como estão e não mudem.

Na terceira categoria, predomínio da operatividade, os pedagogos retomam a visão sistêmica, a ideia do fazer coletivo, da história institucional, como se constata nas falas: "A escola é um sistema dentro de outros sistemas." (P13); "Vamos começar o ano diferente. Para os alunos também, fizeram um tour pela escola. A semana pedagógica começou diferente? Tour histórico, apresentar a escola [...]" (P16); "É preciso reunir mais os professores, escutar mais [...] Para ser grupo é preciso o compartilhamento de algo comum." (P16) (informações verbais).

A operatividade caracteriza-se por ser um movimento que permite a aprendizes aprender, promove questionamentos, desestabiliza certezas, propõe escolhas, discussões e articulações de conhecimentos. É um movimento que ensina a pensar (BARBOSA, 2007).

Quando a operatividade acontece nos grupos aparece o aprender coletivo, momento em que o coordenador de grupo aparece como "copensor" - neologismo criado por Pichon-Rivière (2005) -, ou seja, aquele que pensa com o grupo e contribui para que este crie, se comunique, se aprofunde e amplie conhecimentos, articulando-os com as vivências.

\subsection{GRUPO: UMA UNIDADE EM FUNCIONAMENTO}

Outro instrumento de pesquisa utilizado neste artigo foi a tarefa do $6 .^{\circ}$ encontro, que teve como consigna: "Observar um grupo de professores em determinada tarefa e 
destacar, por escrito, elementos que o caracterizam como uma unidade em funcionamento, ou seja, como um grupo." (informação verbal).

Após a leitura dos relatos das tarefas, constatou-se que o conjunto de pedagogos observou seus professores em situações de hora-atividade ou em reuniões de planejamento.

As palavras mais utilizadas para conceituar "grupo" foram: afinidade, diálogo, compartilhamento, ajuda, amor, interação, união, reunião diária, cooperação, liberdade de escolha e objetivo comum.

Os pedagogos escolares demonstraram dificuldade em compreender grupo como uma unidade em funcionamento porque na maioria dos relatos reconheceram grupo como um ajuntamento de pessoas, cada um fazendo sua atividade, por exemplo: "Em observação aos professores no período de hora-atividade foi possível perceber que se organizam com afinidades, porém cada sujeito com seus afazeres, no caso cada professor estava com o seu notebook." (PI2) (informação verbal).

Destaca-se ainda o seguinte relato, que se aproxima um pouco mais da concepção de grupo, como trabalhado na formação continuada: "Escolhi observar um grupo de professoras que realiza o planejamento de forma unificada, adaptando-o conforme suas necessidades individuais. [...] desenvolve coletivamente estratégias de ensino, confecção de materiais diferenciados, jogos [...]" (P13) (informação verbal).

Assim se percebeu que os conceitos de grupo e comunicação ainda se encontram dissociados, pouco articulados, mas que o grupo de pedagogos participantes da formação continuada já apresenta indícios de assimilação do conteúdo trabalhado, demonstrando nas falas e ações algumas articulações desses conceitos.

\section{CONSIDERAÇÕES FINAIS}

Ao considerar que o objetivo deste artigo é identificar a articulação que os pedagogos escolares estabeleceram entre a informação recebida, as vivências reflexivas durante a formação continuada sobre comunicação e grupo e a prática já desenvolvida no espaço da escola, concluiu-se que há dissociação entre o fazer cotidiano e o discurso por eles adotado.

Assim, constatou-se que os conceitos de grupo e comunicação ainda se encontram pouco articulados para os pedagogos da pesquisa. De modo ingênuo, distantes do conceito de grupo e comunicação, entendem eles que o trabalho em um clima agradável e 
colaborativo já se caracteriza como um trabalho grupal ou ao contrário, sendo a divergência de ideias características de não pertença ao grupo.

Os participantes da pesquisa, por não trabalharem, na maioria das vezes, sob a óptica da observação e da escuta e também por não serem respaldados pelo conhecimento de que a escola deveria ser entendida como um grupo, em processo dinâmico, e que é impossível não comunicar, acabam fazendo leituras da dinâmica escolar e de seus fenômenos de modo simplista. Dessa forma, ficam distantes dos conceitos que suscitam o olhar investigativo, do processo reflexivo que esse olhar provoca e da dinâmica participativa necessária para compor um grupo produtivo.

Não basta que a escola viva um clima afetivo emocional sem aparentes atritos nem se espera que essa comunidade não viva seus conflitos e tensões, próprios dos espaços em que as pessoas se veem como diferentes. A concepção de grupo está relacionada, sobretudo, ao enfrentamento das diferenças e à busca de compreensão, se não for possível o consenso.

Os conceitos de grupo e comunicação, entrelaçados, constituem ferramenta essencial para que os pedagogos possam ler o contingente escolar e promover intervenções eficazes.

Desse modo, é imprescindível que os protagonistas da escola sejam entendidos como uma unidade funcional e, como tal, partilhem as ações, os pensamentos que as sustentam e seus resultados, como uma produção do e para o grupo.

0 pedagogo instrumentalizado para trabalhar o grupo a que pertence, tendo como ferramenta os pressupostos da comunicação humana, terá mais possibilidade de produzir uma prática educacional democrática, que respeite as individualidades e o grupo, em uma dialética de formação humana que considera a equidade como valor da escola.

\section{REFERÊNCIAS}

ÁVILA, L. A. As tensões entre a individualidade e a grupalidade. Revista da SPAGESP, v. 11, n. 2, p. 4-9, 2010.

BARBOSA, L. M. S. Psicopedagogia no âmbito grupal. Operatividade - um instrumento para o desenvolvimento em grupos de aprendizagem. In: ZENÍCOLA, A. M.; BARBOSA, L. M. S.; CARLBERG, S. Psicopedagogia: saberes/olhares/fazeres. São José dos Campos: Pulso, 2007. p. 127-167.

CAMPOS, E. F. E. Os desafios da coordenação pedagógica: partilhando responsabilidades. In: FRANCO, M. A. S.; CAMPOS, E. F. E. (org.). A coordenação do trabalho pedagógico na escola: processos e práticas. Santos: Editora Universitária Leopoldianum, 2016. p. 125-139. 
COLTRO, A. A fenomenologia: um enfoque metodológico para além da modernidade. Caderno de Pesquisas em Administração, v. 1, n. 11, 1. ${ }^{\circ}$ trim., 2000.

CUNHA, N. de B;; BORUCHOVITCH, E. Percepção e conhecimento de futuros professores sobre seus processos de aprendizagem. Pro-posições, v. 27, n. 3, p. 31-56, set./dez. 2016.

FERNANDES, A. A mulher escondida na professora. Porto Alegre: Artes Médicas, 1994.

PICHON-RIVIÉRE, E. 0 processo grupal. São Paulo: Martins Fontes, 2005.

POOLI, J. P.; FERREIRA, V. M. R. Pedagogos construindo suas identidades: entre a descrição e escolhas. Educar em Revista, n. 1, p. 19-37, jun. 2017. Edição Especial.

PORTILHO, E. et al. A instituição que aprende sob o olhar da Psicopedagogia. Rio de Janeiro: Wak, 2018.

SAMPAIO, J. et al. Limites e potencialidades das rodas de conversa no cuidado em saúde: uma experiência com jovens no sertão Pernambucano. Interface, Botucatu, v. 18, suppl. 2, p. 1299-1312, 2014.

VISCA. J. Clínica psicopedagógica: epistemologia convergente. Porto Alegre: Artes Médicas, 1987.

WATZLAWICK, P.; BEAVIN, J. H.; JACKSON, D. Pragmática da comunicação humana. São Paulo: Cultrix, 1999.

Endereço para correspondência: Rua Imaculada Conceição, 1155, Prado Velho, 80215-901, Caixa Postal 17315, Curitiba, Paraná, Brasil; eveliseportilho@gmail.com 
